\title{
Equity of Health Resources Allocation in Rural Guangxi from 2016 to 2019: An Empirical Analysis
}

Shangyuhui Huang ( $\sim 124518513 @ q q . c o m)$

Guilin Medical University,Guangxi Medical University https://orcid.org/0000-0003-1324-2212

FENG Qi-ming

Guangxi Medical University

Research

Keywords: Equity, Primary health care institutions, Health resource, Minority areas

Posted Date: August 4th, 2021

DOI: https://doi.org/10.21203/rs.3.rs-764252/v1

License: (c) (i) This work is licensed under a Creative Commons Attribution 4.0 International License. Read Full License 


\section{Abstract}

Background: Since 2009, the main task of the new health reform in China is to increase the equity of health resources allocation in primary health care institutions. Health policies and strategies have been established to increase the capacity of PHC services, with improved equity as the most important goal. The objective of this study is to analyze the status quo and equity of health resources distribution in rural Guangxi from 2016 to 2019.

Methods: Descriptive statistics analysis was used to analyze the status quo of health resource allocation in rural health center in Guangxi from 2016 to 2019. Lorenz curve, Gini coefficient and Theil index were used to evaluate the equity of health resource allocation in rural health center in Guangxi from 2016 to 2019, from three dimensions of population, geography and economy.

Results: From 2016 to 2019, the total amount of health resources in rural health center in Guangxi was increased, but the professional title and education background of health workers is still low. In 2019, the Gini coefficient was 0.085-0.217 geographically, $0.080-0.367$ demographically and 0.135-0.340 economically. The total Theil index was 013-0.211, and the majority of the contribution rate of within regions was greater than the between regions. Conclusion: From 2016 to 2019, the distribution of health resources in rural Guangxi was uneven among regions, and with great differences within regions.

\section{Background}

Since 2009 , China has launch the new health reform, which has a strong focus on primary health care (PHC). Reasonable health resources allocation determine the efficiency of health care services [1]. The equity of health resources allocation in rural areas should be improved, which is the key of the new health reform in China since 2009 [2]. Furthermore, the current COVID-19 pandemic exacerbated the weaknesses of health care system. China has put forward higher requirements for PHC service. Revitalizing PHC systems is of great importance to improve health outcomes and be better prepare for the next global pandemic. Currently, the problem of difficult and high cost of medical service is still the central part and a prime concern of the new health reform in China, therefore, PHC system should be strengthened.

In China, Rural health center provides general medical care and basic public health services in rural areas. Rural health center is the main subject of $\mathrm{PHC}$ system and rural health prevention [3]. Rural health work is a focal point of health works, which concerns to protect rural productivity, revitalize rural economy and maintain overall situation of social development. It has great meanings in improving the whole nation's health. Previous studies shown that improving the equity of health resources allocation in rural and remote regions is of great significance for promoting health equity [4].

Guangxi Zhuang Autonomous Region is one of the five ethnic minority regions in China, with the largest number of ethnic minorities in China, which accounts for $37 \%$ of its population [4]. The majority of regions in Guangxi are economically underdeveloped remote mountainous and minority areas[5, 6]. There are 11 ethnic minorities in Guangxi including Zhuang, Yao, Miao, Dong, Mulam, Maonan, Hui, Yi, Shui and so on [7]. Guangxi located in the southern China, boarding on Vietnam. The economy development of Guangxi is lagging and the health resources are relatively deficient in frontier minority areas [8].

Inequity in the distribution of health resources seriously hinders the overall improvement of health, which is a concern in the health reform and Healthy Guangxi 2030 strategy. The gap in health resources allocation and health service capacity between rural and urban areas is becoming worse, despite the government's favorable investment policies for the rural areas [9]. Various studies have proved that the equity of health resources in rural areas needs to be optimized [10]. A similar study uses a countrywide Facility Survey to collected data in Saudi Arabia, found that health resources are more concentrated in urban areas than rural areas [11].

The evaluation of equity of health resources in rural areas could help health policy makers to identify the bottlenecks and the take appropriate actions to further optimize the equity of limited health resources in rural areas. Therefore, this study aims to analyze the current situation and equity of health resources allocation in rural Guangxi from 2016 to 2019, using Lorenz curve, Gini coefficient and Theil index, from three dimensions of population, geography and economy (Gross Domestic Product, GDP). Results from this study could contribute to the understanding and development of pro-equity policies that can strengthen national health systems and improve access to quality health services for the under-served areas to achieving universal health coverage.

\section{Methods}

\section{Data sources}

Demographic and geographic area data was sourced from Guangxi Statistical Yearbook 2017-2020 [12-15]. Data related to Rural health center was obtained from Guangxi Health Statistics Yearbook 2017-2020. Microsoft Excel 2019 was used to calculate the Gini coefficient, Theil index and drawn Lorenz curve.

\section{Equity assessment}




\section{Gini coefficient and Lorenz curve}

Gini coefficient, Lorenz curve and Theil index has been identified as the superior tool for assessing the equity of resources allocation [16]. The Gini coefficient is derived from the Lorenz curve, which reflecting the ratio of the area between the curve and the diagonal line, to the whole area below the $45^{\circ}$ line [17]. The following formula was used to calculate the Gini coefficient:

$\mathrm{S}_{\mathrm{B}}=\frac{1}{2} \mathrm{p}_{1} \mathrm{q}_{1}+\frac{1}{2} \sum_{i=1}^{n-1}(\mathrm{qi}+\mathrm{qi}+1)\left(p_{i+1}-p_{i}\right), \mathrm{i}=1,2,3 \ldots \ldots \mathrm{n}(1)$

$\mathrm{G}=1-\mathrm{p}_{1} \mathrm{q}_{1}-\sum_{i=1}^{n-1}(\mathrm{qi}+\mathrm{qi}+1)\left(p_{i+1}-p_{i}\right), \mathrm{i}=1,2 \varangle 3 \ldots \ldots \mathrm{n}(2)$

Where $S_{B}$ is the area bounded by the Lorenz curve and the axes; $G$ standards for the value of the Gini coefficient, pi is the cumulative percentage of population/GDP/geographical area in each group, and qi is the cumulative percentage of health resources in each group.

$\mathrm{G}$ ranges from 0 to 1 , the lower the $G$, the higher the degree of equity. In addition, $G<0.2$ indicates absolutely equity in the allocation of health resources, $\mathrm{G}$ between 0.2 to 0.3 indicates relatively equality, $\mathrm{G}$ between 0.3 to 0.4 indicates lower equity level, $\mathrm{G}$ between from 0.4 to 0.5 indicates highly inequality, $\mathrm{G}>0.5$ indicates extreme inequity [18].

Theil index

Based on the geographical location, 14 prefecture-level cities in Guangxi can be divided into 5 geographical regions as follows: eastern, southern, western, northern and middle part of Guangxi [19]. Northern Guangxi includes Guilin; Mid-Guangxi includes Liuzhou, Laibin; Eastern Guangxi includes Wuzhou, Hezhou, Yulin, Guigang; Southern Guangxi includes Nanning, Chongzuo, Beihai, Qinzhou, Fangchenggang; and Western Guangxi includes Baise and Hechi.

Compared with the Gini coefficient, Theil index could analyze the contribution rate between and within each group to the total, which is complementary to the Gini coefficient [20]. Theil index ranges from 0 to 1, the smaller the value, the higher the degree of equity [21]. The following formula was used to calculate the Theil index:
(1) $\mathrm{T}=\sum_{\mathrm{n}=1}^{\mathrm{n}} \mathrm{Pi}^{*} * \log \left(\frac{\mathrm{Pi}}{\mathrm{Y}_{\mathrm{i}}}\right)$
(2) $\mathrm{T}_{\text {woul }}=\mathrm{T}_{\text {nathio }}+\mathrm{T}_{\text {between }}$
(3) $\mathrm{T}_{\text {witiin }}=\sum_{\mathrm{g}=1}^{\mathrm{k}} \mathrm{Pg} * \mathrm{Tg}$
(4) $\mathrm{T}_{\text {betruete }}=\sum_{8=1}^{k} \mathrm{Pg} *\left(\frac{\mathrm{Pg}}{\mathrm{Yg}}\right)$

Where $\mathrm{T}$ is the Theil index, $\mathrm{T}_{\text {total }}$ is the total Theil index, $\mathrm{T}_{\text {within }}$ is the within group Theil index, $\mathrm{T}_{\text {between }}$ is the between group Theil index; $\mathrm{Pi}$ is the proportion of population/economic (GDP) /geographical area of each city in the total of the region; Yi is the ratio of the number of health resources of each city in the population/economy/geographical area to the total; $\mathrm{Pg}$ is the proportion of the population/economy/geographical area of each city in the in the total; $\mathrm{Yg}$ is the proportion of the total health resources of each region in the total of the whole region; $\mathrm{Tg}$ is the Theil index of each region.

\section{Indicators}

Previous study has been identified health worker, equipment as constituting quality of primary care [22]. Two groups of indicators were selected to reflecting the general information of health resources distributions and equity of health resources allocation, respectively [23, 24]. General information of health resources allocation was measured by the total number of rural health centers (institutions)/ health care beds in the rural health centers (beds)/ health workers in the rural health centers (health workers)/doctors in the rural health centers (doctors)/ nurses per 1,000 rural population, institutions/ beds/ health workers/ doctors/ nurses per square kilometer $\left(\mathrm{Km}^{2}\right)$, and the ratio of doctors to nurses in Guangxi. Institutions, health workers and beds were selected as objects of equity assessment [17].

\section{Results}

General information of health resource distribution in rural Guangxi

\section{Comparative analysis of per capita health resource distribution in different}


In 2019, the average number of institutions per 1,000 rural population in rural Guangxi was 0.03, which was lower than that of China, Eastern China, Mid-China and Western China regions. The number of beds per 1,000 rural population is 1.41, lower than that of China and western China regions. The number of health worker per 1,000 rural population is 1.59, lower than the average number of China, Eastern China and Western China regions. The number of doctors per 1,000 rural population was 0.4 , lower than that of China, Eastern China, Mid-China and Western China regions. The number of nurses per 1,000 rural population was 0.046 , lower than that of China, Eastern China, Mid-China and Western China regions. In Guangxi, the average number of institutions per 1,000 rural population in Yulin was the highest, while the average number of institutions per 1,000 rural population in Nanning was the lowest (Table 1).

\section{Comparative analysis of per square kilometer health resource distribution in different regions}

In 2019, the average number of institutions, beds, health workers, doctors and nurses per $\mathrm{Km}^{2}$ in Guangxi were $0.005,0.29,0.33,0.08$ and 0.1 , respectively, which were lower than the Mid-China region. In Guangxi, the average number of rural health resources per $\mathrm{Km}^{2}$ in Baise, Hechi, Laibin and Chongzuo were lower than the average number of Guangxi (Table 1).

Table 1

Rural health resource allocation in Guangxi in 2019

\begin{tabular}{|c|c|c|c|c|c|c|c|c|c|c|}
\hline \multirow[t]{2}{*}{ Region } & \multicolumn{2}{|l|}{ Institution } & \multicolumn{2}{|l|}{ Bed } & \multicolumn{2}{|c|}{ Health Workers } & \multicolumn{2}{|l|}{ Doctor } & \multicolumn{2}{|l|}{ Nurse } \\
\hline & $\begin{array}{l}10^{3} \\
\text { pooulation }\end{array}$ & $\begin{array}{l}10^{3} \\
M^{2}\end{array}$ & $\begin{array}{l}10^{3} \\
\text { pooulation }\end{array}$ & $\begin{array}{l}10^{3} \\
M^{2}\end{array}$ & $\begin{array}{l}10^{3} \\
\text { pooulation }\end{array}$ & $\begin{array}{l}10^{3} \\
M^{2}\end{array}$ & $\begin{array}{l}10^{3} \\
\text { pooulation }\end{array}$ & $\begin{array}{l}10^{3} \\
M^{2}\end{array}$ & $\begin{array}{l}10^{3} \\
\text { pooulation }\end{array}$ & $\begin{array}{l}10^{3} \\
M^{2}\end{array}$ \\
\hline China & 0.07 & 0.004 & 1.48 & 0.14 & 1.56 & 0.15 & 0.91 & 0.05 & 0.71 & 0.04 \\
\hline Eastern China & 0.05 & 0.005 & 1.34 & 0.22 & 1.68 & 0.28 & 1.02 & 0.1 & 0.72 & 0.07 \\
\hline Mid-China & 0.06 & 0.011 & 1.43 & 0.48 & 1.34 & 0.45 & 0.91 & 0.16 & 0.67 & 0.12 \\
\hline Western China & 0.09 & 0.002 & 1.68 & 0.01 & 1.71 & 0.07 & 0.84 & 0.02 & 0.76 & 0.02 \\
\hline Guangxi & 0.02 & 0.005 & 1.77 & 0.29 & 1.99 & 0.33 & 0.29 & 0.08 & 0.32 & 0.1 \\
\hline Eastern Gui & 0.04 & 0.007 & 2.98 & 0.48 & 3.38 & 0.54 & 0.89 & 0.14 & 0.99 & 0.16 \\
\hline Southern Gui & 0.05 & 0.005 & 3.15 & 0.36 & 3.32 & 0.38 & 0.82 & 0.09 & 1.01 & 0.12 \\
\hline Westhern Gui & 0.07 & 0.005 & 1.89 & 0.12 & 2.99 & 0.19 & 0.68 & 0.04 & 0.79 & 0.05 \\
\hline Nothern Gui & 0.06 & 0.005 & 1.82 & 0.17 & 2.7 & 0.25 & 0.83 & 0.08 & 0.77 & 0.07 \\
\hline Mid-Gui & 0.06 & 0.005 & 3.43 & 0.28 & 3.57 & 0.29 & 0.87 & 0.07 & 1 & 0.08 \\
\hline Nanning & 0 & 0.005 & 0.4 & 0.43 & 0.41 & 0.45 & 0.11 & 0.12 & 0.13 & 0.15 \\
\hline Liuzhou & 0.07 & 0.005 & 3.03 & 0.23 & 3.54 & 0.27 & 0.92 & 0.07 & 0.98 & 0.07 \\
\hline Guilin & 0.06 & 0.005 & 1.82 & 0.17 & 2.7 & 0.25 & 0.83 & 0.08 & 0.77 & 0.07 \\
\hline Wuzhou & 0.04 & 0.005 & 2.48 & 0.29 & 3.45 & 0.4 & 0.92 & 0.11 & 1.04 & 0.12 \\
\hline Beihai & 0.03 & 0.006 & 3.31 & 0.58 & 3.29 & 0.57 & 0.9 & 0.16 & 1.05 & 0.18 \\
\hline Fangchenggang & 0.07 & 0.005 & 2.85 & 0.18 & 3.48 & 0.22 & 0.88 & 0.06 & 0.98 & 0.06 \\
\hline Qinzhou & 0.03 & 0.005 & 3.18 & 0.58 & 3.01 & 0.54 & 0.68 & 0.12 & 0.89 & 0.16 \\
\hline Guigang & 0.03 & 0.007 & 2.52 & 0.52 & 3.22 & 0.66 & 0.92 & 0.19 & 0.84 & 0.17 \\
\hline Yulin & 0.04 & 0.009 & 3.67 & 0.84 & 3.38 & 0.77 & 0.86 & 0.2 & 1.02 & 0.23 \\
\hline Baise & 0.08 & 0.005 & 1.36 & 0.09 & 3.05 & 0.19 & 0.67 & 0.04 & 0.76 & 0.05 \\
\hline Hezhou & 0.06 & 0.005 & 2.71 & 0.25 & 3.62 & 0.34 & 0.88 & 0.08 & 1.14 & 0.11 \\
\hline Hechi & 0.07 & 0.004 & 2.46 & 0.16 & 2.94 & 0.19 & 0.68 & 0.04 & 0.83 & 0.05 \\
\hline Laibin & 0.06 & 0.006 & 3.88 & 0.35 & 3.61 & 0.33 & 0.81 & 0.07 & 1.02 & 0.09 \\
\hline Chongzuo & 0.07 & 0.005 & 2.18 & 0.16 & 2.83 & 0.21 & 0.63 & 0.05 & 0.77 & 0.06 \\
\hline
\end{tabular}

\section{Time trends of health resources allocation in rural Guangxi from 2016 to 2019}

From 2016 to 2019, the average number of institutions, nurses per 1,000 rural population and the ratio of doctors to nurses in Guangxi were lower Loading [MathJax]/jax/output/CommonHTML/jax.js I and Western China regions. The number of beds, health workers and doctors per 1,000 rural 
population in rural Guangxi were higher than that of China, Eastern China, Mid-China and Western China regions. Compared to the China, Eastern China, Mid-China and Western China regions, the average annual growth rate (AAGR) of beds and doctors per 1,000 rural population was the highest, while the ratio of doctors to nurses was the lowest (Table 2).

Table 2

Health resources allocation in rural Guangxi from 2016 to 2019

\begin{tabular}{|c|c|c|c|c|c|c|}
\hline Health resources & Region & 2016 & 2017 & 2018 & 2019 & AAGR(\%) \\
\hline \multirow[t]{5}{*}{ Institutions per 1,000 rural population } & Guangxi & 0.02 & 0.02 & 0.02 & 0.02 & 0 \\
\hline & China & 0.07 & 0.07 & 0.07 & 0.07 & 0 \\
\hline & Eastern China & 0.05 & 0.05 & 0.05 & 0.05 & 0 \\
\hline & Mid-China & 0.06 & 0.06 & 0.06 & 0.06 & 0 \\
\hline & Western China & 0.09 & 0.09 & 0.09 & 0.09 & 0 \\
\hline \multirow[t]{5}{*}{ Beds per 1,000 rural population } & Guangxi & 1.49 & 1.56 & 1.65 & 1.77 & 5.91 \\
\hline & China & 1.26 & 1.35 & 1.43 & 1.48 & 5.51 \\
\hline & Eastern China & 1.14 & 1.21 & 1.26 & 1.34 & 5.54 \\
\hline & Mid-China & 1.24 & 1.32 & 1.37 & 1.43 & 4.87 \\
\hline & Western China & 1.42 & 1.52 & 1.57 & 1.68 & 5.76 \\
\hline \multirow[t]{5}{*}{ Health workers per 1,000 rural population } & Guangxi & 1.74 & 1.81 & 1.91 & 1.99 & 4.58 \\
\hline & China & 1.36 & 1.42 & 1.49 & 1.56 & 4.68 \\
\hline & Eastern China & 1.45 & 1.51 & 1.56 & 1.68 & 5.03 \\
\hline & Mid-China & 1.24 & 1.27 & 1.27 & 1.34 & 2.62 \\
\hline & Western China & 1.41 & 1.5 & 1.56 & 1.71 & 6.64 \\
\hline \multirow[t]{5}{*}{ Doctors per 1,000 rural population } & Guangxi & 0.85 & 0.89 & 0.92 & 0.96 & 4.14 \\
\hline & China & 0.82 & 0.84 & 0.87 & 0.54 & -13.00 \\
\hline & Eastern China & 0.92 & 0.94 & 0.97 & 0.63 & -11.86 \\
\hline & Mid-China & 0.86 & 0.88 & 0.88 & 0.53 & -14.90 \\
\hline & Western China & 0.7 & 0.74 & 0.77 & 0.47 & -12.43 \\
\hline \multirow[t]{5}{*}{ Nurses per 1,000 rural population } & Guangxi & 0.24 & 0.25 & 0.26 & 0.29 & 6.51 \\
\hline & China & 0.58 & 0.62 & 0.62 & 0.71 & 6.97 \\
\hline & Eastern China & 0.61 & 0.64 & 0.69 & 0.72 & 5.68 \\
\hline & Mid-China & 0.55 & 0.57 & 0.59 & 0.67 & 6.80 \\
\hline & Western China & 0.59 & 0.66 & 0.7 & 0.76 & 8.81 \\
\hline \multirow[t]{5}{*}{ Ratio of doctors to nurses } & Guangxi & 0.91 & 0.88 & 0.85 & 0.82 & -3.41 \\
\hline & China & 0.7 & 0.73 & 0.97 & 0.78 & 3.67 \\
\hline & Eastern China & 0.66 & 0.69 & 0.95 & 0.71 & 2.46 \\
\hline & Mid-China & 0.64 & 0.65 & 0.95 & 0.74 & 4.96 \\
\hline & Western China & 0.84 & 0.9 & 1.02 & 0.91 & 2.70 \\
\hline
\end{tabular}

\section{Structure of health workers in rural Guangxi}

In 2019, the proportion of Junior college degree was acecounted for the largest (44.72\%), followed by the Technical secondary school degree (43.77\%), while the Senior High school and below degree was accounted for the least (0.57\%). The proportion of No titles/ unknown was accounted for the largest (40.87\%), while the proportion of Senior professional title was accounted for the least (0.04\%) (Table 3).

\section{Fairness assessment}


Table 3

The proportion of education background and professional titles (\%)

\begin{tabular}{|lllll|}
\hline Structure/ Personnel & Doctor & Nurse & Health technical personnel & Health worker \\
\hline Degree & & & & \\
\hline Postgraduate & 0.18 & 0.01 & 0.06 & 0.06 \\
\hline Undergraduate & 20.32 & 5.01 & 10.79 & 10.79 \\
\hline Junior college & 54.33 & 42.16 & 44.72 & 44.72 \\
\hline Technical Secondary school & 24.82 & 52.57 & 43.86 & 43.77 \\
\hline Senior High school and Below & 0.34 & 0.18 & 0.57 & 0.57 \\
\hline Professional titles & & & & 0.04 \\
\hline Senior & 0.09 & 0.03 & 0.04 & 1.45 \\
\hline Middle & 3.44 & 1.17 & 1.45 & 9.91 \\
\hline Junior & 16.1 & 13.15 & 9.91 & 17.82 \\
\hline Technical expert & 30.35 & 19.89 & 17.82 & 29.92 \\
\hline Assistant & 24.82 & 33.18 & 29.92 & 40.87 \\
\hline No titles/unknown & 25.2 & 32.58 & 40.87 & 9010 \\
\hline
\end{tabular}

\section{Changes of Lorenz curve and Gini coefficient from 2016 to 2019}

From 2016 to 2019, G against GDP size was higher than that of population and geographic size. Compared with 2016, except for institutions, G by geographic size in 2019 was greater than 0.3 . G by population was $0.068-0.217$ : where $0.187-0.217$ for institutions, $0.118-0.160$ for beds, $0.068-$ 0.088 for health workers, which means that the distribution of the health resources was relatively equity. In addition, the $\mathrm{G}$ by geographic area was 0.080-0.367: where $0.080-0.081$ for institutions, $0.289-0.357$ for beds, $0.266-0.367$ for health workers, indicating that the distribution of the health resources was the lower equity level. Moreover, G by GDP was $0.135-0.354$ : where $0.336-0.340$ for institutions, $0.249-0.354$ for beds, 0.135-0.276 for health workers, indicating that the distribution of the health resources exhibits lower equity level (Table 4).

By the population size, the Lorenz curves of the health workers was closest to the absolute equity curve, while the institutions was the farthest (Fig. 1-2). This finding affirmed that the equity of health workers was the best while the institutions was the worst against population dimension. By the geographic size, the Lorenz curve of the institutions was the closest to the absolute equity curve, while the beds was the farthest (Fig. 3-4). This finding verified that the equity of institutions was the best and that of the health workers was the worst in terms of the geographical dimension. By the GDP size, the Lorenz curve of the health workers was the closest to the absolute equity curve, while the institutions was the farthest (Fig. 5-6). This finding verified that the equity of health workers was the best and that of the institutions was the worst in terms of the GDP dimension. Furthermore, the trends of $\mathrm{G}$ of health workers fluctuated the most, dropping from 0.276 in 2016 to 0.135 in 2019 . G of institutions in geographic and population size fluctuated slightly, and all of them were less than 0.2 (Fig. 7-9). 
Table 4

Gini coefficient of health resources in rural Guangxi from 2016 to 2019

\begin{tabular}{|lllll|}
\hline Dimension /Year & 2016 & 2017 & 2018 & 2019 \\
\hline Population size & & & & \\
\hline Institution & 0.215 & 0.187 & 0.216 & 0.217 \\
\hline Bed & 0.118 & 0.125 & 0.16 & 0.147 \\
\hline Health Workers & 0.088 & 0.086 & 0.068 & 0.085 \\
\hline Geographic size & & & & \\
\hline Institution & 0.081 & 0.08 & 0.08 & 0.08 \\
\hline Bed & 0.289 & 0.289 & 0.363 & 0.357 \\
\hline Health Workers & 0.266 & 0.205 & 0.257 & 0.367 \\
\hline GDP size & & & & \\
\hline Institution & 0.336 & 0.338 & 0.338 & 0.34 \\
\hline Bed & 0.283 & 0.354 & 0.249 & 0.289 \\
\hline Health Workers & 0.276 & 0.223 & 0.166 & 0.135 \\
\hline
\end{tabular}

\section{Theil index and contribution rate from 2016 to 2019}

By population size, $T_{\text {total }}$ was lower than 0.1. By geographic size, except for beds, $T_{\text {total }}$ showed a decreasing trend from 2016 to 2019 . By GDP size, except for health worker, $T_{\text {total }}$ showed a trend of increasing year by year. By population and geographic size, except for institutions, the contribution rate of Thiel index of health resources in rural Guangxi was $T_{\text {between }}<T_{\text {within. }}$. In GDP size, except for beds, the contribution rate of Theil index of all

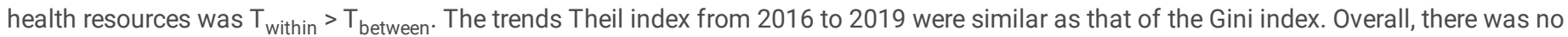
significant change in the inter-group and intra-group differences in the contribution rate of Theil index (Table 5 and Fig. 10-12).

Table 5

Theil index and contribution rate (\%) of health resources in rural Guangxi from 2016 to 2019

\begin{tabular}{|c|c|c|c|c|c|c|c|c|c|}
\hline \multirow[t]{2}{*}{ Dimension /Year } & \multicolumn{3}{|c|}{ Institutions } & \multicolumn{3}{|l|}{ Beds } & \multicolumn{3}{|c|}{ Health Workers } \\
\hline & $\mathrm{T}_{\text {total }}$ & $\mathrm{T}_{\text {between }}$ & $\mathrm{T}_{\text {within }}$ & $\mathrm{T}_{\text {total }}$ & $\mathrm{T}_{\text {between }}$ & $\mathrm{T}_{\text {within }}$ & $\mathrm{T}_{\text {total }}$ & $\mathrm{T}_{\text {between }}$ & $\mathrm{T}_{\text {within }}$ \\
\hline \multicolumn{10}{|l|}{ Population size } \\
\hline 2016 & 0.08 & 54.95 & 45.05 & 0.029 & 24.94 & 75.06 & 0.019 & 19.27 & 80.73 \\
\hline 2017 & 0.08 & 54.77 & 45.23 & 0.031 & 26.78 & 73.22 & 0.019 & 20.34 & 79.66 \\
\hline 2018 & 0.08 & 54.81 & 45.27 & 0.03 & 30.35 & 69.65 & 0.018 & 23.37 & 76.63 \\
\hline 2019 & 0.081 & 53.51 & 46.49 & 0.041 & 26.54 & 73.46 & 0.018 & 25.97 & 74.03 \\
\hline \multicolumn{10}{|l|}{ Geographic size } \\
\hline 2016 & 0.013 & 47.11 & 52.89 & 0.134 & 60.03 & 39.97 & 0.111 & 69.97 & 30.03 \\
\hline 2017 & 0.013 & 47.36 & 52.64 & 0.135 & 63.75 & 36.25 & 0.106 & 69.56 & 30.44 \\
\hline 2018 & 0.014 & 47.8 & 52.2 & 0.136 & 60.18 & 39.82 & 0.104 & 69.21 & 30.79 \\
\hline 2019 & 0.013 & 53.29 & 46.71 & 0.211 & 64.48 & 35.52 & 0.107 & 68.87 & 31.13 \\
\hline \multicolumn{10}{|l|}{ GDP size } \\
\hline 2016 & 0.186 & 61.62 & 38.38 & 0.132 & 48.15 & 51.85 & 0.129 & 55.71 & 44.29 \\
\hline 2017 & 0.188 & 61.55 & 38.45 & 0.139 & 49.14 & 50.86 & 0.13 & 56.18 & 43.82 \\
\hline 2018 & 0.188 & 61.75 & 38.25 & 0.133 & 47.67 & 52.33 & 0.129 & 57.69 & 42.31 \\
\hline 2019 & 0.19 & 61.64 & 38.36 & 0.136 & 38.16 & 61.84 & 0.128 & 58.89 & 41.11 \\
\hline
\end{tabular}




\section{Discussion}

From the absolute number point of view, compared to the China, Eastern China, Mid-China and Western China regions, the AAGR of beds and doctors per 1,000 rural population was the highest. Furthermore, from 2016 to 2019, the number of health resources per 1,000 rural population in Guangxi is higher than that of China, Eastern China, Mid-China and Western China regions. Illustrating that the health service capacity in rural Guangxi has been improved from 2016 to 2019. However, the ratio of doctors and nurses in rural Guangxi was decreased from 0.91 in 2016 to 0.82 in 2019. This may be partially due to the fact that China has attaches great importance to the training of doctors, while neglecting the nurses [25]. Furthermore, from 2016 to 2019, the primary health investment in Guangxi was mainly used for the infrastructure construction of primary medical institutions, while ignoring the introduction and training of health workers in rural health centers to some extent, which was consistent with the findings of other study [26]. In terms of the structure of health workers in rural Guangxi, the proportion of Junior college degree (44.72\%) was the largest, while the Postgraduate degree was the least $(0.06 \%)$. Furthermore, the proportion of No titles/unknown was the largest $(40.87 \%)$, while the proportion of High professional title was the least $(0.04 \%)$. In rural areas in China, health workers are badly qualified, due to the lack of the training opportunities, which was consistent with the findings of Zhu and Xiao [27].

Studies in China also found that the quality health resources tend to be concentrated in the general hospitals [28, 29]. On account of the "Siphon effect", the majority of the health resources are concentrated in Nanning, the most developed city in Guangxi, while the underdeveloped rural areas are lack of health resources, this observation was in line with other studies $[8,19,30]$. Low wages and restricted career development have often been blamed for the loss of health workers in rural health centers [31]. Meanwhile, general hospitals developed far more rapidly than rural health centers [32]. It may impose a risk of further enlarging the health service capacity gap between developed areas and remote poor regions, which is against the governmental effort to strengthen primary health service capacity in the new health reform. Although the government has invested heavily in PHC, the health service capacity of rural health centers still lags behind the hospital sector [6].

From 2016 to 2019 , $G$ of population size $(0.068-0.217)$ was lower than that of geographic size $(0.080-0.367)$. Moreover, the trends of Theil index and Gini coefficient were similar from 2016 to 2019. The Chinese government were based on the number of population to allocating health resource, while ignoring the different geographical factors of each region [24]. Correspondingly, the fairness of health resource allocation by population size was much better than geographic size, which was consistent with the findings of other researches [33, 34]. By GDP and geographical size, the contribution rate were: $T_{\text {between }}>T_{\text {within }}$. It suggests that the regional economic differences might be the main reason for the unfairness of health resources in rural Guangxi, which was in line with the other study [19].

Furthermore, Baise, Hechi, Chongzuo and Laibin are the cities inhabited by ethnic minorities in Guangxi, where the population of ethnic minorities accounts for more than $75 \%$ of the total [5]. In 2019, the health resources per $\mathrm{Km}^{2}$ in the ethnic minorities region in Guangxi was higher than the average level of Guangxi. In recent years, the government has formulated documents and increased investment for PHC to promote the development of health services in ethnic minorities regions. Currently, the health workers working in rural health centers have several encouragements: short-term centralism training, more wages and welfare, and cash bonuses. Furthermore, "Internet + medical" model was implemented in remote poor ethnic regions to promote the sharing of health resources, and encouraged the hospitals in the developed cities in Guangxi such as Nanning and Liuzhou, to provide health support for poor and remote ethnic minority regions, including technological resources, health manpower and financing.

Based on our analysis, several policy implications to improve the overall equity of health resources allocation in rural Guangxi was as follows. First of all, the government guidance should be strengthened and increase the financial support to further reducing the gap between the urban and rural areas. Secondly, the geographic of health resource allocation in vast and sparsely populated areas need to be addressed. Moreover, the health institutions are supposed to introduce adequate health workers in remote and economically underdeveloped areas by giving extra subsidies and other preferential policies to ameliorate the inequity status. Last but not least, health workers determined the prosperity and decline of rural health centers to some extent. The salary and welfare of health workers in rural areas should be improved gradually. In order to reduce the inequity of health resources allocation in Guangxi, stakeholders, including policymakers, governments, health workers and patients, should strive to cooperate jointly in order to ameliorate the situation. In addition, investments for PHC needs to be increased significantly in underdeveloped regions.

\section{Conclusion}

In conclusion, this study provides suggestive evidence for the equity in the distribution of health resources in rural Guangxi by elucidating the phanaina trande of honlth manuman allonation from 2016 to 2019. The continuous growth in the number of health resources in rural areas would Loading $[$ MathJax]/jax/output/CommonHTML/jax.js 
further meet the health needs of rural residents. This study found that the equity of health resources in rural Guangxi is significantly higher by population than by geographic area and GDP, which substantiates the results of previous studies [8, 21]. In addition, the equity status in the distribution of the institutions, beds and health workers in rural Guangxi have deteriorated since 2016. Current development of health manpower

practice in multiple sites and telemedicine are very encouraging, which would greatly improve the PHC service capacity and alleviate the problem of shortage of health resources in rural areas. In addition, the assessment for fair distribution of other health resources needs to be performed by using multiple analysis methods.

\section{Declarations}

\section{Acknowledgement}

This study was supported by grants from the Health Committee of Guangxi Zhuang Autonomous Region.

\section{Declarations}

The data used in this study is publicly available and no permission is required to access the data.

\section{Funding}

This study was supported by the Health Committee of Guangxi Zhuang Autonomous Region (03301219007D).

\section{Availability of data and materials}

The database generated during and/or analyzed during the current study are available from the corresponding author on reasonable request.

\section{Authors' contributions}

QF formulated the research concept and developed the primary framework of the study; SH contributed to the final manuscript; all authors were involved in data collection. The final manuscript submitted for publication was read and approved by all authors.

\section{Ethics}

Not applicable. This study was not a study on human beings and the data collected has no relationship with patients' medical records data, therefore, ethics statement was not needed.

\section{Consent for publication}

Not applicable.

Data sharing: No additional data are available.

\section{Competing interests}

All authors have no competing financial interest.

\section{Author details}

1 Guilin Medical University, 2 Huan Cheng Bei Road, Qi xing District, Guilin 541004, Guangxi Zhuang Autonomous Region, China.

2 Health Policy Research Center of Guangxi Medical University, Guangxi Medical University, 22 Shuang Yong Road, Qing Xiu District, Nanning 530021, Guangxi Zhuang Autonomous Region, China.

\section{References}

1. Zhao Z, Dai S, Sun Z, et al. Status Quo and Equity of Health Care Resources Allocation in China from 2016 to 2019: An Empirical Analysis. Science Journal of Public Health. 2021;9(3).

2. Chen J, Xu S, Gao J. The Mixed Effect of China's New Health Care Reform on Health Insurance Coverage and the Efficiency of Health Service Utilisation: A Longitudinal Approach. INT J ENV RES PUB HE. 2020;17(5).

3. Gijs W. The 2018 Astana Declaration on Primary Health Care, is it useful? J GLOB HEALTH. 2019;9(1).

4. Chen M, Chen W, Zhao Y. New evidence on financing equity in China's health care reform - A case study on Gansu province, China. BioMed Central. 2012;12(1). 
5. Huang J. On the Development of Minorities -inhabited Areas in Guangxi from the Perspective of Growth Pole Theory-partântof studies on the constructing model district of national unity and progress in Guangxi. Guangxi Ethnic Res. 2013(01):40-45.

6. Peng R, Deng M, Qin X, et al. Research on the current situation and equity of health resource allocation in Guangxi from 2015 to 2017 . Chin Health Policy Res. 2020;13(3):57-63.

7. Peng R, Qin X, Wei X, et al. Equity analysis of health human resources in Guangxi Based on agglomeration degree. Modern Preventive Med. 2019;46(19):3561-4, 3584.

8. Sun J. Equality in the distribution of health material and human resources in Guangxi: evidence from Southern China. BMC Research Notes. 2017;10(1).

9. Huan W, SarahEve D, Huan Z, et al. Health, economic, and social implications of COVID-19 for China's rural population. AGR ECONBLACKWELL. 2021;52(3).

10. Obinna O, Ojiugo MC, Chukwuedozie A, et al. Analysis of equity and social inclusiveness of national urban development policies and strategies through the lenses of health and nutrition. INT J EQUITY HEALTH. 2021;20(1).

11. Quds AS, Taghred A, Ahlam A, et al. The capacity of primary health care facilities in Saudi Arabia: infrastructure, services, drug availability, and human resources. BMC HEALTH SERV RES. 2021;21(1).

12. Guangxi Bureau of Statistics. Guangxi statistical yearbook 2020. Beijing: China Statistics Press; 2020.

13. Guangxi Bureau of Statistics. Guangxi statistical yearbook 2019. Beijing: China Statistics Press; 2019.

14. Guangxi Bureau of Statistics. Guangxi statistical yearbook 2018. Beijing: China Statistics Press; 2018.

15. Guangxi Bureau of Statistics. Guangxi statistical yearbook 2017. Beijing: China Statistics Press; 2017.

16. Li Y, Zhang M, Liu H. Research on the Equity and Efficiency of Maternal and Child Health Care Resources Allocation in Sichuan Province from 2012 to 2016. Med Soc. 2019;32(10):9-12.

17. Jian J, Jianxiang W, Xiaoyi M, et al. Equality of Medical Health Resource Allocation in China Based on the Gini Coefficient Method. IRAN J PUBLIC HEALTH. 2015;44(4).

18. Schneider M. The Discovery of the Gini Coefficient: Was the Lorenz Curve the Catalyst? HIST POLIT ECON. 2021;53(1).

19. Fan D, Qin X, Deng M, et al. Health resource allocation and equity in Guangxi from 2015 to 2018. Chin Health Econ. 2020;39(6):50-4.

20. Song P, Ren Z, Chang X, et al. Inequality of Paediatric Workforce Distribution in China. INT J ENV RES PUB HE. 2016;13(7).

21. Huimin Y, Shuangyan Y, Da H, et al. Equity analysis of Chinese physician allocation based on Gini coefficient and Theil index. BMC HEALTH SERV RES. 2021;21(1).

22. McCollum R, Chen L, ChenXiang T, et al. Experiences with primary healthcare in Fuzhou, urban China, in the context of health sector reform: a mixed methods study. The International Journal of Health Planning and Management. 2014;29(2).

23. Zhang T, Xu Y, Ren J, et al. Inequality in the distribution of health resources and health services in China: hospitals versus primary care institutions. BioMed Central. 2017;16(1).

24. Zhang Y, Wang Q, Jiang T, et al. Evaluation on equality and efficiency of primary health care resource allocation in mainland China. BioMed Central. 2018;17(1).

25. Wu Q, Huang A, Chen M, et al. Equity of nursing human resource allocation in Anhui Province. Med Soc. 2020;33(2):22-5.

26. Lu Z, Meng Q, Wang Y. Evaluation on equality of rural health resource allocation before and after the new medical reform in China. Chin Public Health. 2017;33(8):1203-5.

27. Zhu W, Xiao Y. Evaluation on equality of Health human resource allocation in China since the new Medical reform. Chin health Eco. 2020;39(2):51-4.

28. Cao F, Xian Y, Bai T, et al. Comparative analysis of equity of health resource allocation in urban and rural basic medical institutions in Shandong Province. Chin health Eco. 2017;36(12):55-8.

29. Zhao J, Liu J, Wang S, et al. The Equity Analysis of the Allocation of Health $\mathrm{I}^{1} \mathbf{4}^{2}$ esources Based on Gini Co- efficient and IDW Interpolation Method on the Space in Shandong Province. Chin Health Statistics. 2016;33(01):56-8.

30. Wang X, Luo H, Qin X, et al. Evaluation of performance and impacts of maternal and child health hospital services using Data Envelopment Analysis in Guangxi Zhuang Autonomous Region, China: a comparison study among poverty and non-poverty county level hospitals. INT J EQUITY HEALTH. 2016;15(1).

31. Zhou Y, Lan X, Si M, et al. Analysis on the Health Human Resource Allocation in Guangxi Based on the Hierarchical Diagnosis System. Chin health Eco. 2018;37(07):51-3.

32. Zhang J, Yu Z. Analysis of Benefit Fairness of Primary Health Resources Allocation in Shandong Province. Med Soc. 2018;31(08):5-7.

33. Sun J, Luo H. Evaluation on equality and efficiency of health resources allocation and health services utilization in China. BioMed Central. $2017 ; 16(1)$

Loading [MathJax]/jax/output/CommonHTML/jax.js 
34. Erdenee O, Paramita SA, Yamazaki C, et al. Distribution of health care resources in Mongolia using the Gini coefficient. HUM RESOUR HEALTH. $2017 ; 15(1)$.

\section{Figures}

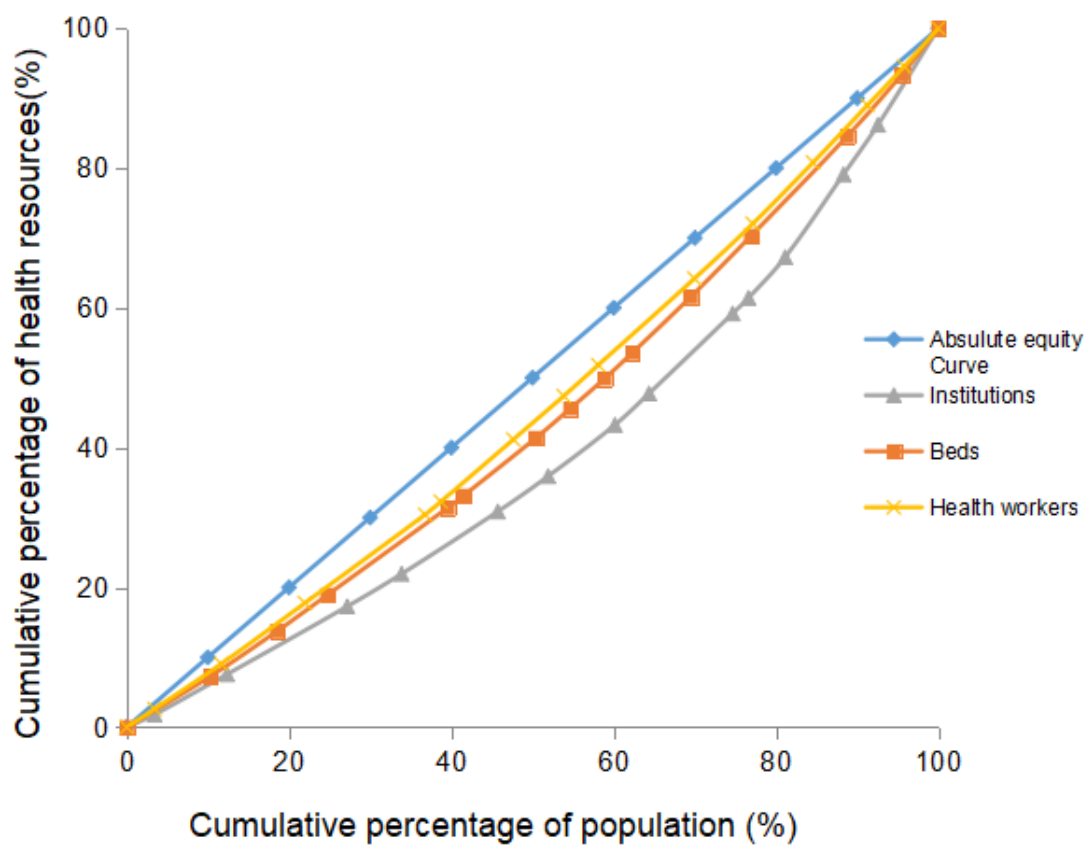

Fig. 1: Lorenz Curve of distribution of the health resources by population in 2016

\section{Figure 1}

See image above for figure legend

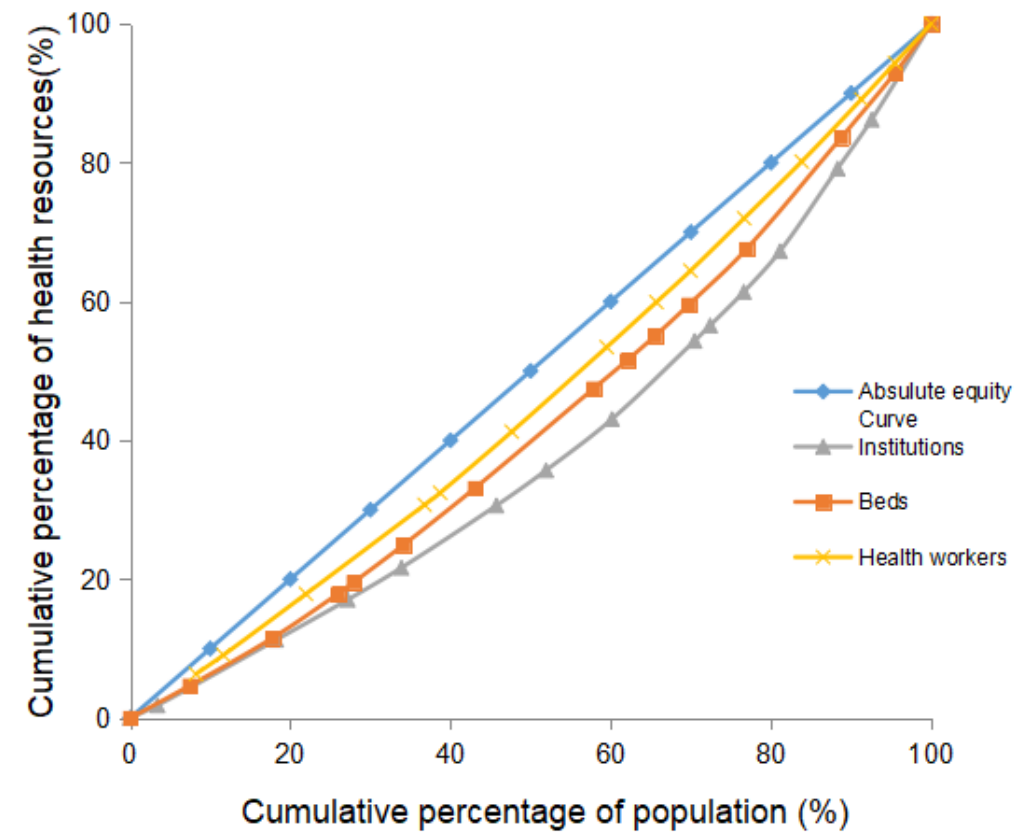

Fig. 2: Lorenz Curve of distribution of the health resources by population in 2019

Figure 2 
See image above for figure legend

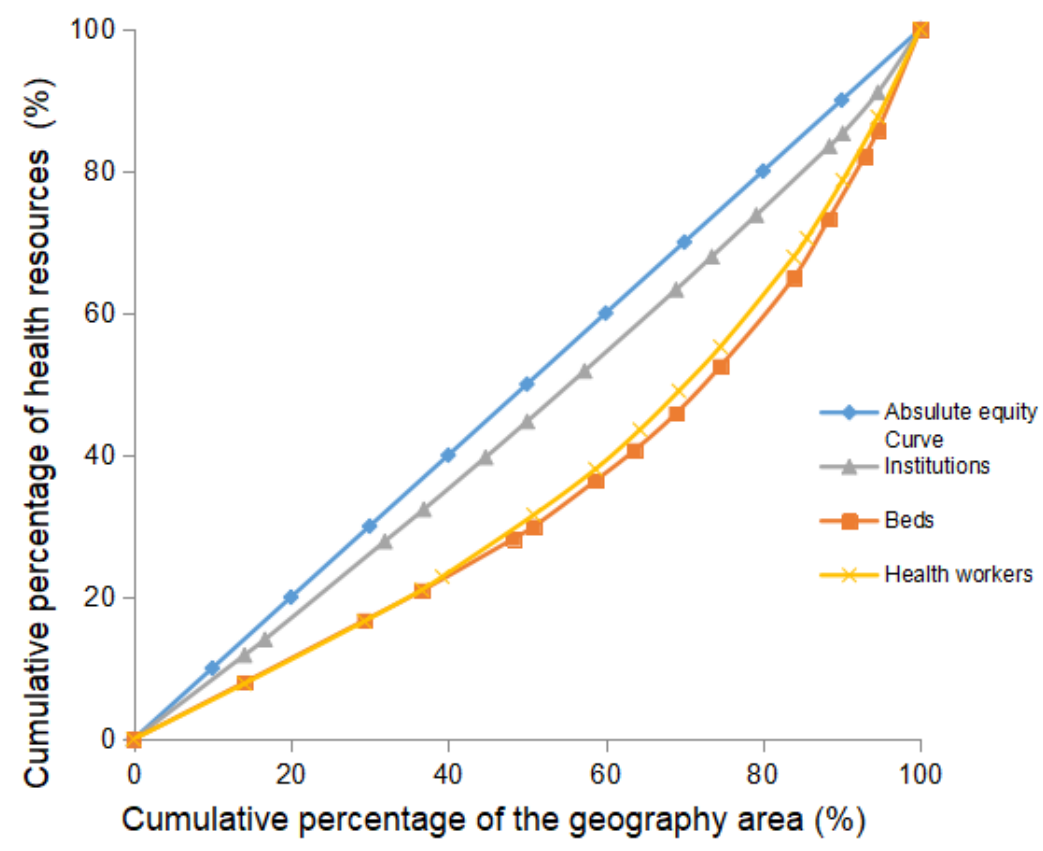

Fig. 3: Lorenz Curve of distribution of the health resources by geographic area in 2016

\section{Figure 3}

See image above for figure legend

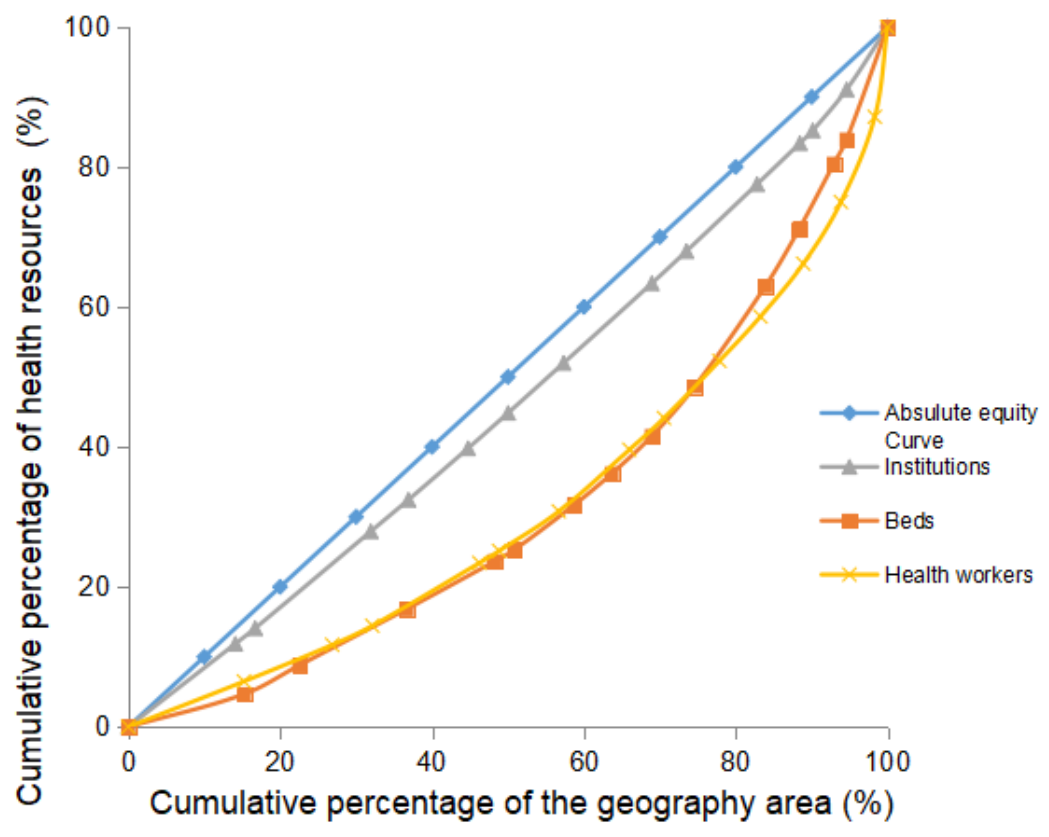

Fig. 4: Lorenz Curve of distribution of the health resources by geographic area in 2019

Figure 4

See image above for figure legend 


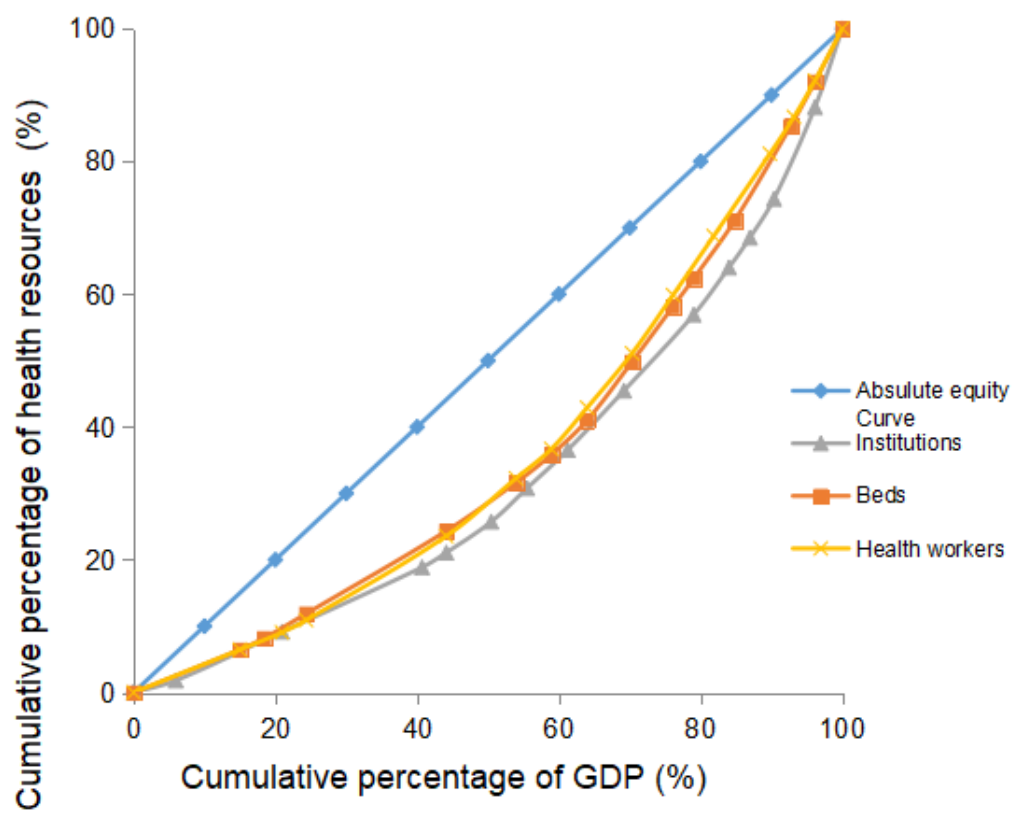

Fig. 5: Lorenz Curve of distribution of the health resources by GDP in 2016

\section{Figure 5}

See image above for figure legend

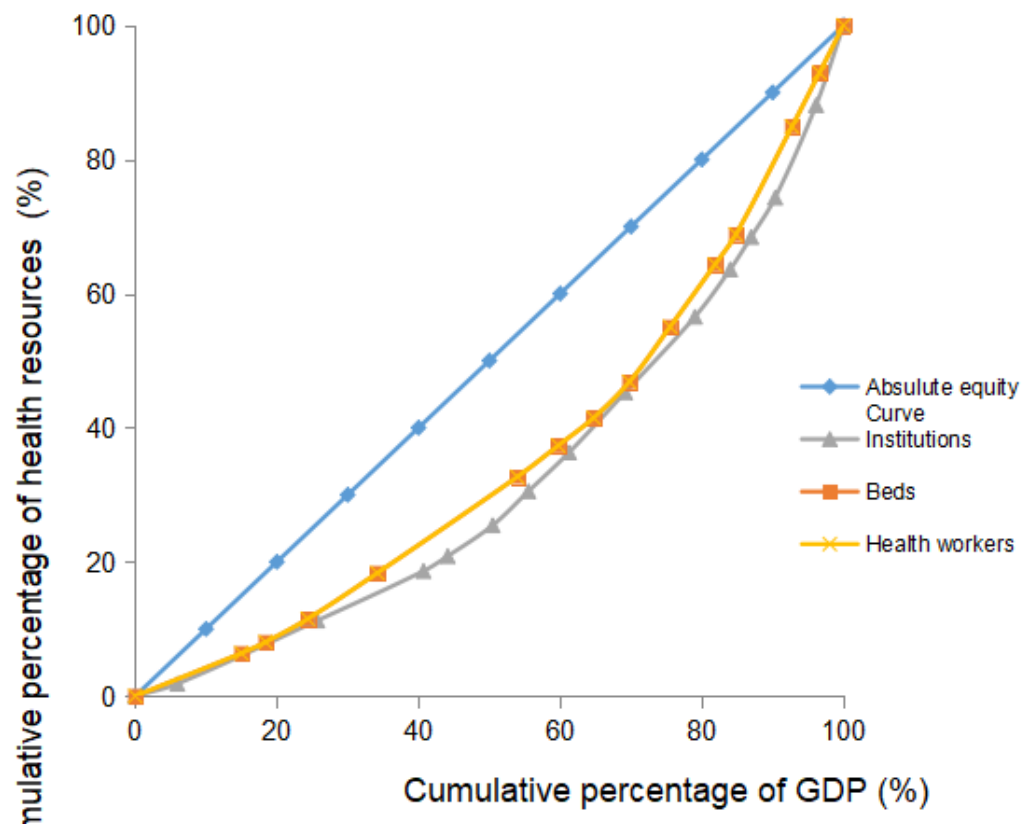

Fig. 6: Lorenz Curve of distribution of the health resources by GDP in 2019

\section{Figure 6}

See image above for figure legend 


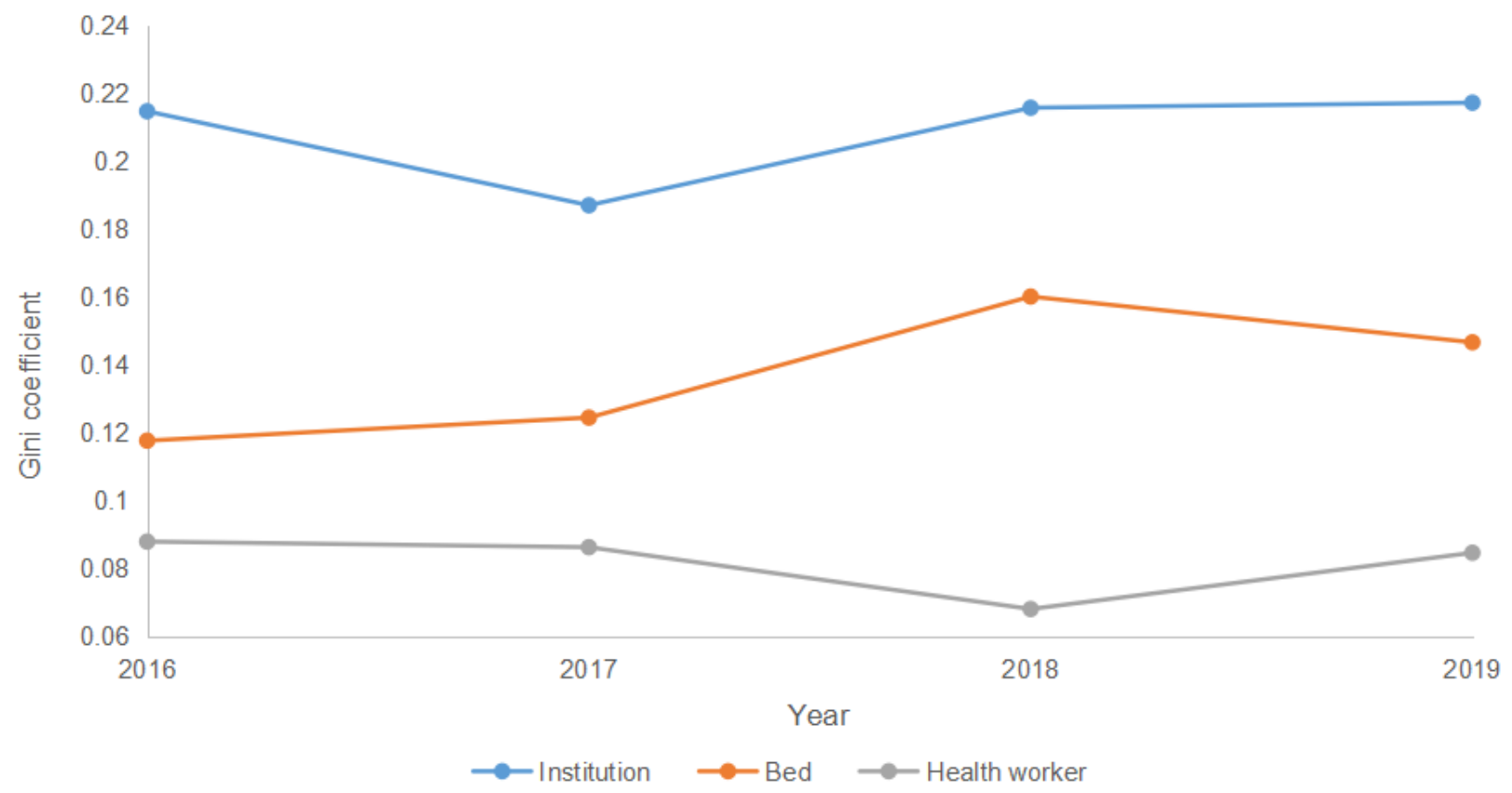

Fig.7 Gini coefficients for health resources in rural Guangxi by population from 2016 to 2019

Figure 7

See image above for figure legend

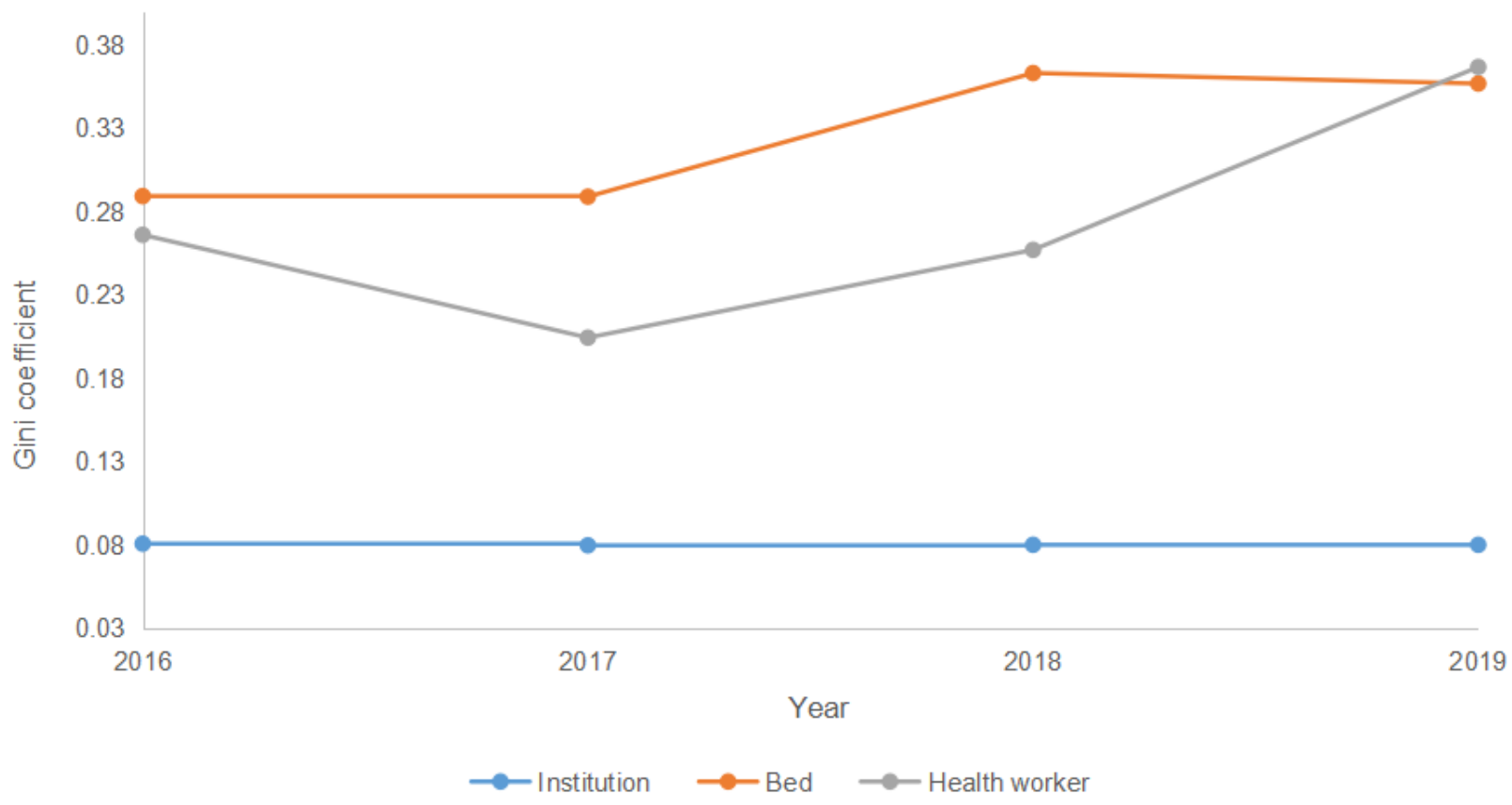

Fig. 8 Gini coefficients for health resources in rural Guangxi by geography area from 2016 to 2019

Figure 8

See image above for figure legend 


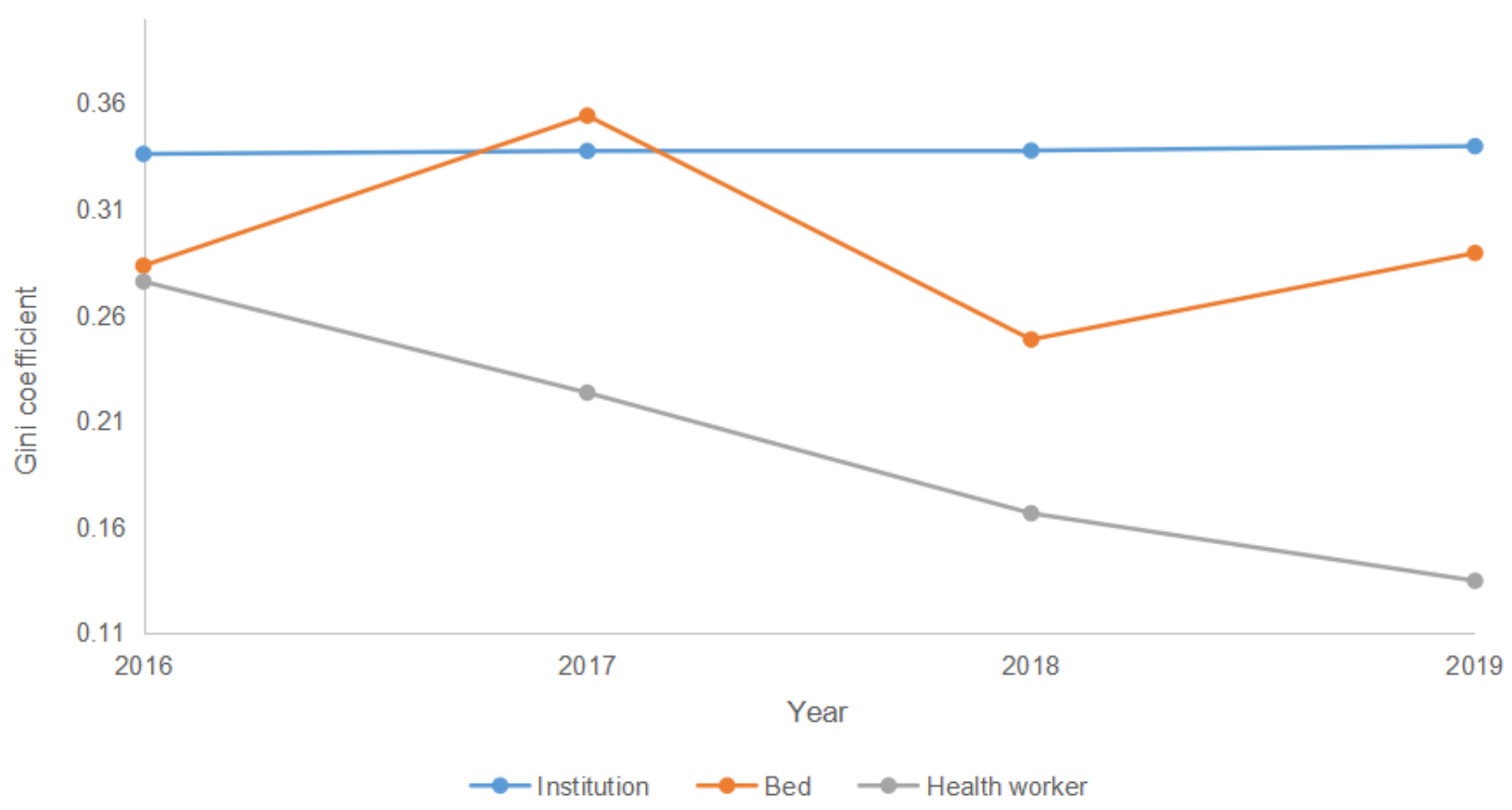

Fig. 9 Gini coefficients for health resources in rural Guangxi by GDP from 2016 to 2019

\section{Figure 9}

See image above for figure legend

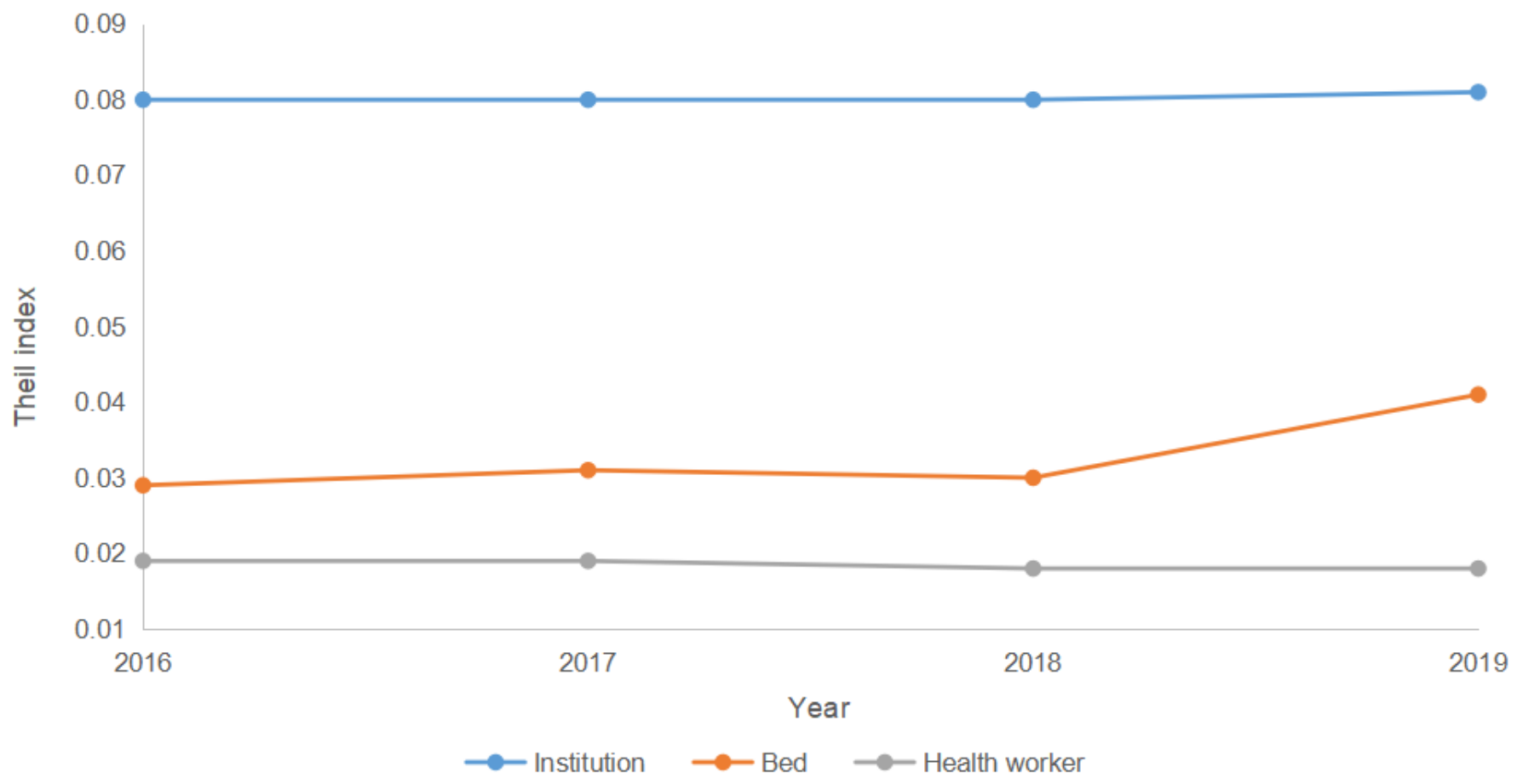

Fig.10 Theil index for health resources in rural Guangxi by population from 2016 to 2019

Figure 10

See image above for figure legend 


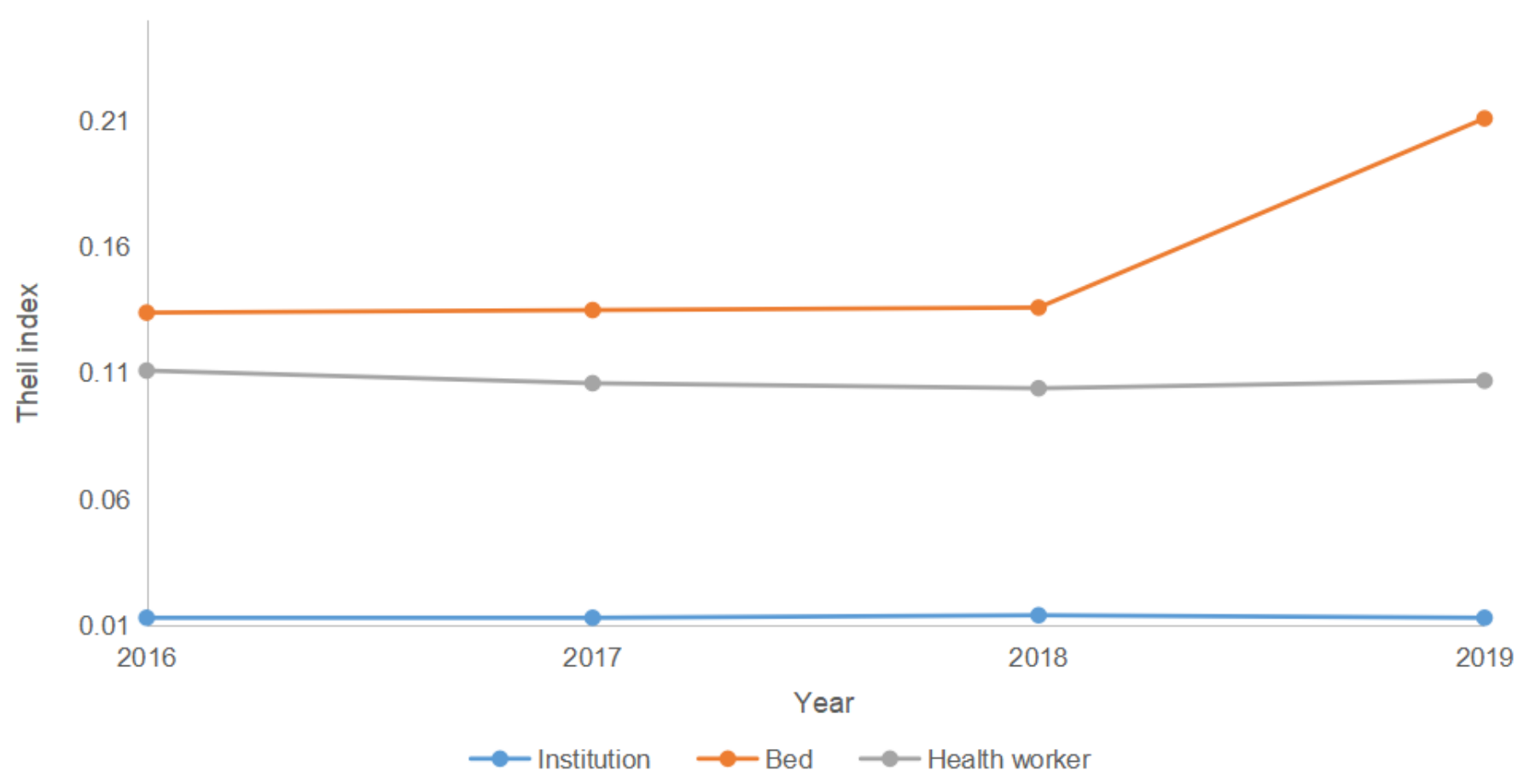

Fig.11 Theil index for health resources in rural Guangxi by geographic area from 2016 to 2019

Figure 11

See image above for figure legend

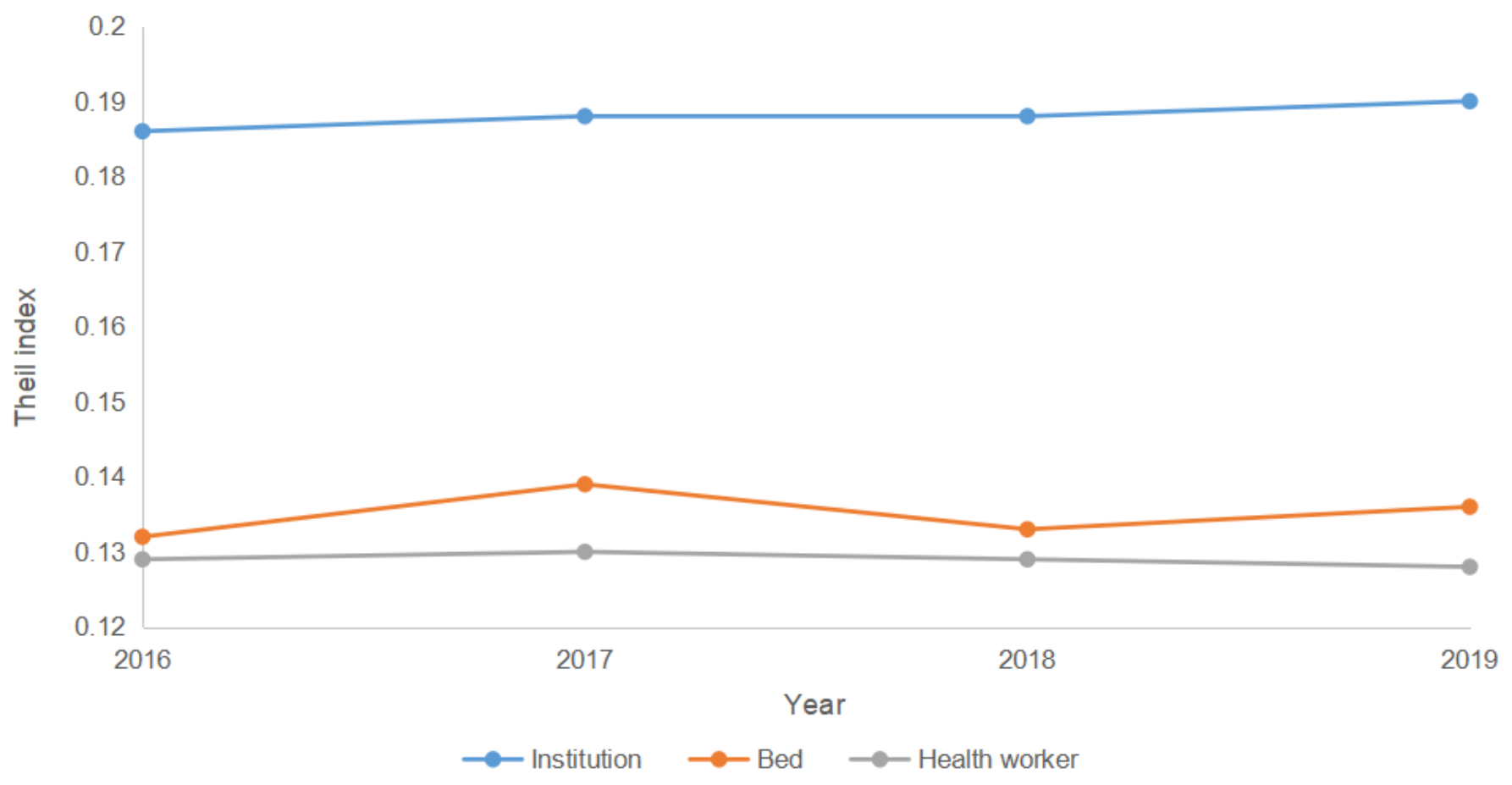

Fig.12 Theil index for health resources in rural Guangxi by GDP from 2016 to 2019

Figure 12

Soo imano ahnve for finuro lanond 